\title{
Reproducibility of Proton Magnetic Resonance Spectroscopic Imaging in Patients with Schizophrenia
}

Alessandro Bertolino, M.D., Joseph H. Callicott, M.D., Safia Nawroz, M.D., Venkata S. Mattay, M.D., Jozef H. Duyn, Ph.D., Gioacchino Tedeschi, M.D., Joseph A. Frank, M.D., and Daniel R. Weinberger, M.D.

Using proton magnetic resonance spectroscopic imaging $\left({ }^{1} H-M R S I\right)$ we found in a previous study a specific pattern of neuronal pathology in patients with schizophrenia as determined by relative loss of signal from $\mathrm{N}$-acetylcontaining compounds (NAA). The purpose of the present study was to assess the reproducibility of the results of ${ }^{1} \mathrm{H}-\mathrm{MRSI}$ both in patients with schizophrenia and in normal controls. We studied twice 10 patients and 10 controls on 2 days separated by, on average, 3 months. Reproducibility was assessed with several statistical procedures including ANOVA, coefficients of variation (CVs) and intra-class correlation coefficients (ICC). Patients showed significant reductions of NAA/creatine-phosphocreatine (CRE) and $N A A /$ choline-containing compounds (CHO) selectively in the hippocampal region (HIPPO) and in the dorsolateral prefrontal cortex (DLPFC) on both experimental days. A repeated measures ANOVA showed no effect of time on metabolite ratios in all subjects. CVs were fairly low (especially for NAA/CRE and CHO/CRE) and did not differ significantly between patients and controls. The ICCs of the ROIs reached statistical significance only in a few instances. The present multislice ${ }^{1} H-M R S I$ study shows that: (1) patients with schizophrenia, when compared as a group to normal controls, show a consistent ${ }^{1} H-M R S I$ pattern of group differences, i.e., bilateral reductions of NAA/CRE and NAA/CHO in HIPPO and DLPFC;

(2) ${ }^{1} H-M R S I$ data in both patients and controls do not show significant changes over this 90-day period; however, absolute metabolite ratios in individuals show low predictability over this time interval; (3) ${ }^{1} \mathrm{H}-\mathrm{MRSI}$ data show relatively low variability (as measured by the CVS) both in patients and normal controls, especially for NAA/ $C R E$ and $C H O / C R E$. [Neuropsychopharmacology 18:1-9, 1998] Published by Elsevier Science Inc.
KEY WORDS: Frontal cortex; Hippocampus;

N-acetyl-aspartate

From the Clinical Brain Disorders Branch (AB, JHC, SN, VSM, DRW), Intramural Research Programs, National Institutes of Health, National Institute of Mental Health, Neurosciences Center at Saint Elizabeths, Washington, DC; and the Neuroimaging Branch (GT), NINDS, and the Laboratory of Diagnostic Radiology Research (JAF), OD, National Institutes of Health, Washington, DC.

Address correspondence to: Daniel R. Weinberger, M.D., National Institute of Mental Health (NIMH), Neuropsychiatric Res. Hospital, NIMH Div. Intramural Res. Prog., Dept. of Health \& Human Services, Martin Luther King Jr. Ave., SE, Washington, DC 20032.

Received July 8, 1996; accepted November 7, 1996.
Proton magnetic resonance spectroscopy $\left({ }^{1} \mathrm{H}-\mathrm{MRS}\right)$ permits acquisition of signals arising from $\mathrm{N}$-acetyl-containing compounds (mainly $\mathrm{N}$-acetyl-aspartate, NAA), choline-containing compounds (mainly phosphocholine and glycerophosphocholine, $\mathrm{CHO}$ ), creatine/phosphocreatine (CRE), and lactate (LAC). NAA is inferred to be a neuronal marker, because it is absent in mature glial cell cultures (Urenjak et al. 1993). Although the function of NAA has not yet been established conclusively, it is regarded as either a marker of neuronal density or of neuronal integrity. The $\mathrm{CHO}$ signal reflects brain choline stores, with major contributions from 
glycerophosphocholine and phosphocholine (Barker et al. 1994a; Miller 1991). Both creatine and phosphocreatine, metabolites involved in cellular energy metabolism, give rise to the CRE signal. LAC is usually present in cells utilizing glycolysis.

Localized ${ }^{1} \mathrm{H}$-MRS has been used to study a variety of brain disorders, including multiple sclerosis (Roser et al. 1995), neoplasm (Alger et al. 1990), epilepsy (Connelly et al. 1994), Down's syndrome (Murata et al. 1993), Huntington's disease (Jenkins et al. 1993), and schizophrenia (Yurgelun-Todd et al. 1996; Renshaw et al. 1995; Nasrallah et al. 1994; Maier et al. 1995; Buckley et al. 1994; Fukuzako et al. 1995). ${ }^{1} \mathrm{H}-\mathrm{MRS}$ has recently evolved to multislice ${ }^{1} \mathrm{H}$-MRS imaging $\left({ }^{1} \mathrm{H}\right.$-MRSI) that permits imaging of signals arising from a large number of small single-volume elements (nominal volume resolution of $0.84 \mathrm{~mL}$ ) within multiple whole brain slices, thus enabling mapping of the spatial extent of chemical abnormalities with improved resolution (Duyn et al. 1993). ${ }^{1} \mathrm{H}-\mathrm{MRSI}$ studies have included patients with cerebellar degeneration (Tedeschi et al. 1996), childhood ataxia with diffuse central nervous system (CNS) hypomyelination (Tedeschi et al. 1995a), adrenoleukodystrophy (Kruse et al. 1994), AIDS dementia complex (Barker et al. 1995), temporal lobe epilepsy (Hetherington et al. 1995), Alzheimer's disease (Meyerhoff et al. 1994), and schizophrenia (Bertolino et al. 1996).

Both localized ${ }^{1} \mathrm{H}-\mathrm{MRS}$ and ${ }^{1} \mathrm{H}-\mathrm{MRSI}$ have been used longitudinally to observe disease progression and response to treatment (Barker et al. 1994b; Bizzi et al. 1995; Vion-Dury et al. 1995; Nakakoshi et al. 1994; Cazzaniga et al. 1994; Arnold et al. 1994; Davie et al. 1994). Nevertheless, reproducibility and stability, key issues in evaluating the clinical potential of proton spectroscopy especially as a tool in longitudinal studies, have not been fully evaluated. Three previous proton spectroscopy studies have specifically addressed the issue of reproducibility in healthy controls (Narayana et al. 1991; Jackson et al. 1994; Charles et al. 1996). Preliminary reproducibility data of ${ }^{1} \mathrm{H}$-MRSI in normals have recently been reported (Tedeschi et al. 1995b). No prior study has addressed this issue in patients with schizophrenia.

The purpose of this study was to assess the reproducibility of ${ }^{1} \mathrm{H}-\mathrm{MRSI}$ in several brain regions, both in patients with schizophrenia and normal controls, including the hippocampal area (HIPPO) and the dorsolateral prefrontal cortex (DLPFC) that have been implicated in the pathophysiology of the disorder (Weinberger and Lipska 1995; Weinberger 1995), and that have been among the sites of previously reported ${ }^{1} \mathrm{H}$-MRS findings (Yurgelun-Todd et al. 1996; Renshaw et al. 1995; Nasrallah et al. 1994; Maier et al. 1995; Buckley et al. 1994; Fukuzako et al. 1995; Bertolino et al. 1996). A secondary objective was to determine the stability of the regionality of neurochemical pathology in a group of patients with schizophrenia (Bertolino et al. 1996).

\section{METHODS}

\section{Subjects}

Ten inpatients (nine men and one woman, mean age $34.8 \pm 5.8$ ) from the National Institute of Mental Health Neuropsychiatric Research Hospital at St. Elizabeths, Washington, DC, volunteered and gave their written informed consent to participate in this study. All patients fulfilled DSM-IV criteria for schizophrenia. All but one were on a stable dose of neuroleptic drugs at the time of the study (Table 1). The controls consisted of 10 healthy volunteers matched for sex, age (mean $32.8 \pm$ 7.4), and handedness. They were recruited both from the community and from the National Institutes of Health (NIH) normal volunteer office. Exclusion criteria included a history of significant head injury, alcohol, or drug abuse, and serious medical/neurological illness. Each subject underwent two scans (day 1 and day 2). The controls had a mean interval between the two scans of $3.1 \pm 2.6$ months (range 2 weeks to 7 months). The patients had a mean interval of $3 \pm 1.4$ months (range 2 weeks to 5 months). There was no statistically signifi-

Table 1. Patient Characteristics

\begin{tabular}{llll}
\hline Patient \# & Day 1 Medication & Day 2 Medication & Diagnosis \\
\hline 1 & risperidone $4 \mathrm{mg}$ & risperidone $8 \mathrm{mg}$ & sch, par \\
2 & clozapine $350 \mathrm{mg}$ & clozapine $350 \mathrm{mg}$ & sch, par \\
3 & risperidone $6 \mathrm{mg}$ & risperidone $6 \mathrm{mg}$ & sch, undif \\
4 & clozapine $600 \mathrm{mg}$ & clozapine $600 \mathrm{mg}$ & sch, par \\
5 & risperidone $7 \mathrm{mg}$ & risperidone $7 \mathrm{mg}$ & sch, par \\
6 & haloperidol $8 \mathrm{mg}$ & haloperidol $8 \mathrm{mg}$ & sch, undif \\
7 & haloperidol $20 \mathrm{mg}$ & haloperidol $18 \mathrm{mg}$ & sch, par \\
8 & haloperidol $10 \mathrm{mg}$ & clozapine $500 \mathrm{mg}$ & sch, undif \\
9 & none & none & sch, par \\
10 & haloperidol $6 \mathrm{mg}$ & haloperidol $6 \mathrm{mg}$ & sch, par \\
\hline
\end{tabular}

Abbreviations: sch, schizophrenia; par, paranoid; undif, undifferentiated. 
cant difference between patients and controls for time between scans. On day 2, subjects were repositioned by using the sylvian fissure as an anatomical reference (vide infra). Day 1 data included results from seven patients and six controls previously reported (Bertolino et al. 1996).

\section{${ }^{1} \mathrm{H}$-MRSI Procedure}

Because the purpose of this study was also to test the reproducibility of our earlier findings, we repeated the same procedures described before (Bertolino et al. 1996) involving the following steps. Multiple slice ${ }^{1} \mathrm{H}$-MRSI was performed on a conventional GE-SIGNA 1.5 Tesla MR imaging system (GE Medical Systems, Milwaukee, WI) equipped with self-shielded gradients using the method of Duyn et al. (1993). The standard quadrature head coil was used in all exams. A sagittal localizer was first obtained (Fast Spin Echo, TR 3500 ms, TE 102 ms), followed by a set of $\mathrm{T}_{1}$-weighted 3-mm thick oblique axial slices (Spin Echo, TR $500 \mathrm{~ms}$, TE $12 \mathrm{~ms}$ ) in a plane parallel to the angle of the sylvian fissure. This orientation was selected to parallel the longitudinal axis of the hippocampus (HIPPO). Five 3-mm thick oblique axial slices were chosen where HIPPO was best represented. These five slices corresponded to the inferior most volume of a set of four 15-mm thick spectroscopic volumes. Phase encoding procedures were used to obtain a $32 \times$ 32 array of spectra from volumes in the selected slice. Each volume element had nominal dimensions of 7.5 $\mathrm{mm} \times 7.5 \mathrm{~mm} \times 15 \mathrm{~mm}(0.84 \mathrm{~mL}$ voxel $)$. Actual volume, based on full width at half maximum (FWHM) after filtering of k-space, was $1.4 \mathrm{~mL}$ (Duyn et al. 1993). The ${ }^{1} \mathrm{H}-\mathrm{MRSI}$ sequence relied on a spin echo slice selection with repetition time (TR) of 2,200 $\mathrm{ms}$ and echo time (TE) of $272 \mathrm{~ms}$ to select the axial slices and to suppress most of the signal arising from lipids in skull marrow and surface tissue. After acquiring the spectroscopic data, $\mathrm{T}_{1}$-weighted images were obtained again at the same location to inspect visually for subject movement. Any visually apparent shift in the location of HIPPO from one scan to the next was considered evidence for movement and was grounds for excluding the study. The entire examination lasted approximately $1 \mathrm{~h}$.

The raw ${ }^{1} \mathrm{H}$-MRSI data were processed on Unix workstations (Sun Mycrosystems, Mountain View, CA) using in-house developed software. First, the location of peaks corresponding to NAA, CHO, CRE, and LAC was automatically determined for all voxels. Voxels in which these metabolite signals could not be identified (e.g., voxels located outside the head and on or near the skull's surface) were then manually nulled. The signal strength in a range of $0.1 \mathrm{ppm}$ around the NAA, CHO, $\mathrm{CRE}$, and LAC signal positions was integrated to produce four $32 \times 32$ arrays of metabolite signals. We studied metabolite signal intensities as ratios of the area un- der each peak: NAA/CRE, NAA/CHO, CHO/CRE. This convention reduces error arising from variations of magnetic field homogeneity and partial volume effects with cerebrospinal fluid.

A rater blind to subject diagnosis utilized the $T_{1}$ weighted coaxial magnetic resonance images (MRIs) to define regions of interest (ROIs). The ROI analysis involved in-house developed software that transfers manually drawn ROIs from the MRIs to the same location on the spectroscopic maps. ROIs were drawn bilaterally in the HIPPO (inclusive of amygdala, hippocampus, and parahippocampal gyrus), DLPFC (all the frontal cortex rostral to the precentral sulcus), superior temporal gyrus (STG), orbitofrontal cortex (ORFC), occipital cortex (OC), anterior and posterior cingulate (respectively, A CING and P CING), centrum semiovale (CSO), prefrontal white matter (FWM), thalamus (TH), and putamen (PU). Voxels that were contained within the original MRI-based ROI but not present on the metabolite maps were removed. Thus, the final calculations were performed only on voxels containing ${ }^{1} \mathrm{H}$ spectra. The program then computed the average value of the areas under each peak in all voxels comprised in that ROI. In this way mean values, separately for NAA, $\mathrm{CHO}$, and CRE, were obtained in each anatomical ROI. To assess reliability of these measurements, another rater blind to diagnosis, independently drew the same ROIs in 10 randomly selected cases (ICC for metabolite ratios in all ROIs $=0.9$ ).

\section{Statistics}

We tested the differences between patients and comparison subjects separately for each metabolite ratio and for each ROI by a two-way repeated measures analysis of variance (ANOVA), with hemisphere (left or right) as the within-group factor and diagnosis (patients or comparison subjects) as the between group factor. Post-hoc analysis was performed by the Tukey honest significance difference (HSD) test. We also performed a separate twoway repeated measures ANOVA, with time (day 1 and day 2) as the within-group factor and diagnosis as the between-group factor, on each ROI for each ratio.

To describe specifically the variability both in patients and normal controls for each ROI, we used the coefficient of variation (CV). The $\mathrm{CV}$ is defined as the standard deviation (SD) divided by the mean. As a measure of reliability, the intraclass correlation coefficient (ICC) (Bartko and Carpenter 1976) was obtained for each ROI for each ratio.

\section{RESULTS}

Figures 1 and 2 show MRIs and metabolite maps of NAA, CHO, and CRE at the level of HIPPO and DLPFC 


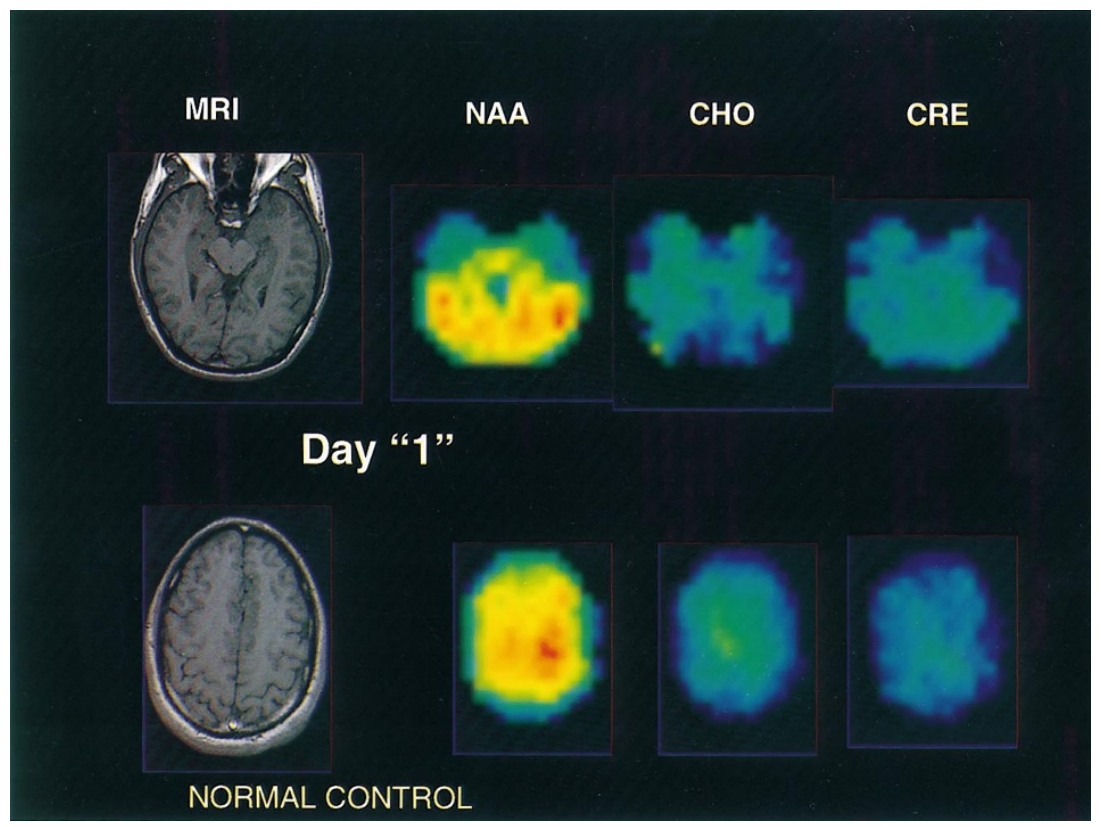

Figure 1. Metabolite signal intensity maps of NAA, CHO, and CRE of a normal control on day 1 . The upper slabs are at the level of HIPPO and the lower at the level of DLPFC (as shown in the coaxial MRI).

of the two repeat studies of a healthy control. Color images are scaled to the highest value of each metabolite signal intensity for each ${ }^{1} \mathrm{H}-\mathrm{MRSI}$ slice, so that the pattern of regional distribution of metabolite signal intensities within the same slice can be compared across days, although color intensity from the same anatomical location cannot be compared across days. Figure 3 shows representative spectra of the same subject from all ROIs in the two experimental days.

On both day 1 and day 2 (Table 2), ANOVA showed in HIPPO a significant effect of diagnosis both for NAA/CRE $(\mathrm{F}=11.5, d f 1,18, p<.003$ on day 1 and $\mathrm{F}=$
11.4, $d f 1,18, p<.003$ on day 2$)$ and NAA/CHO $(\mathrm{F}=$ $6.8, d f 1,18, p<.01$ and $F=7.3, d f 1,18, p<.01)$. Post-hoc analysis showed that patients had a significant bilateral reduction of NAA/CRE $(p<.003$ on day 1 and $p<.003$ on day 2$)$ and NAA/CHO ( $p<.01$ and $p<.01)$. No main effect of hemisphere or interaction with diagnosis was found for NAA/CRE and NAA/CHO both on day 1 and 2. No main effect or interaction was found for $\mathrm{CHO} / \mathrm{CRE}$ on both days.

On both day 1 and day 2 (Table 2), in DLPFC ANOVA showed a significant effect of diagnosis both for NAA/CRE $(\mathrm{F}=24.0, d f 1,18, p<.0001$ and $\mathrm{F}=7.01$,

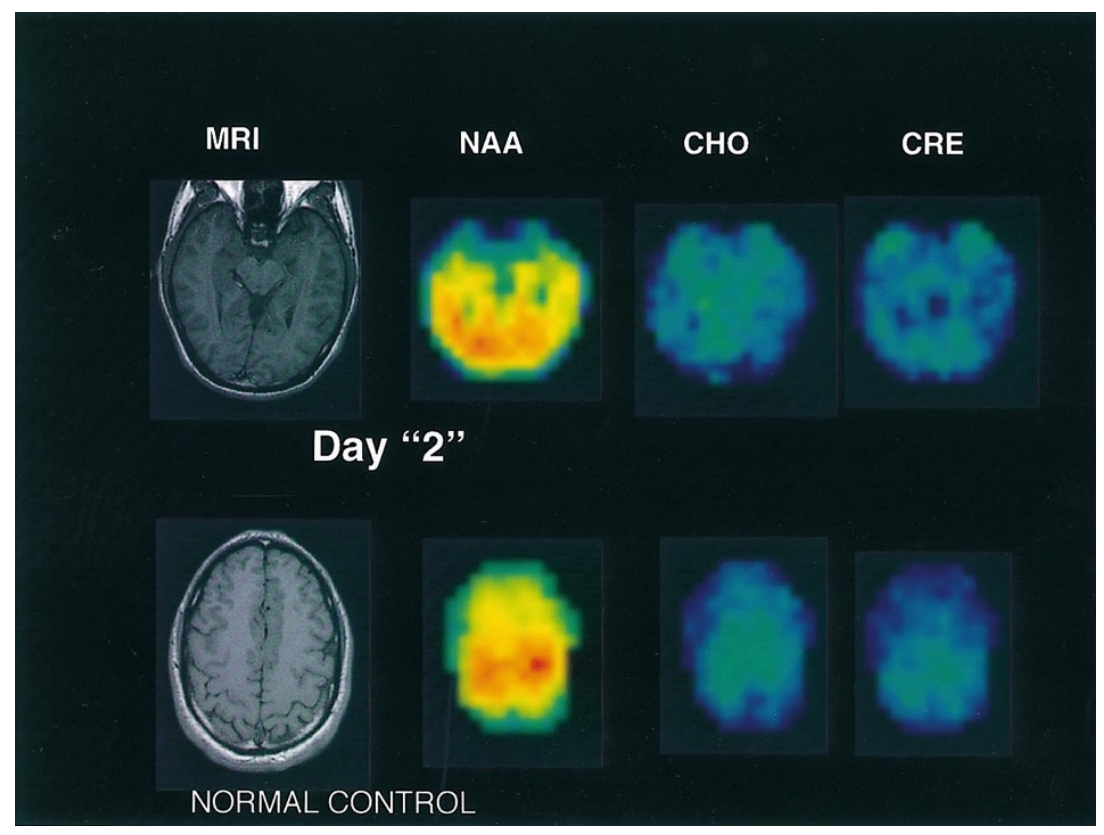

Figure 2. Metabolite signal intensity maps of NAA, CHO, and CRE of the same normal control on day 2. 


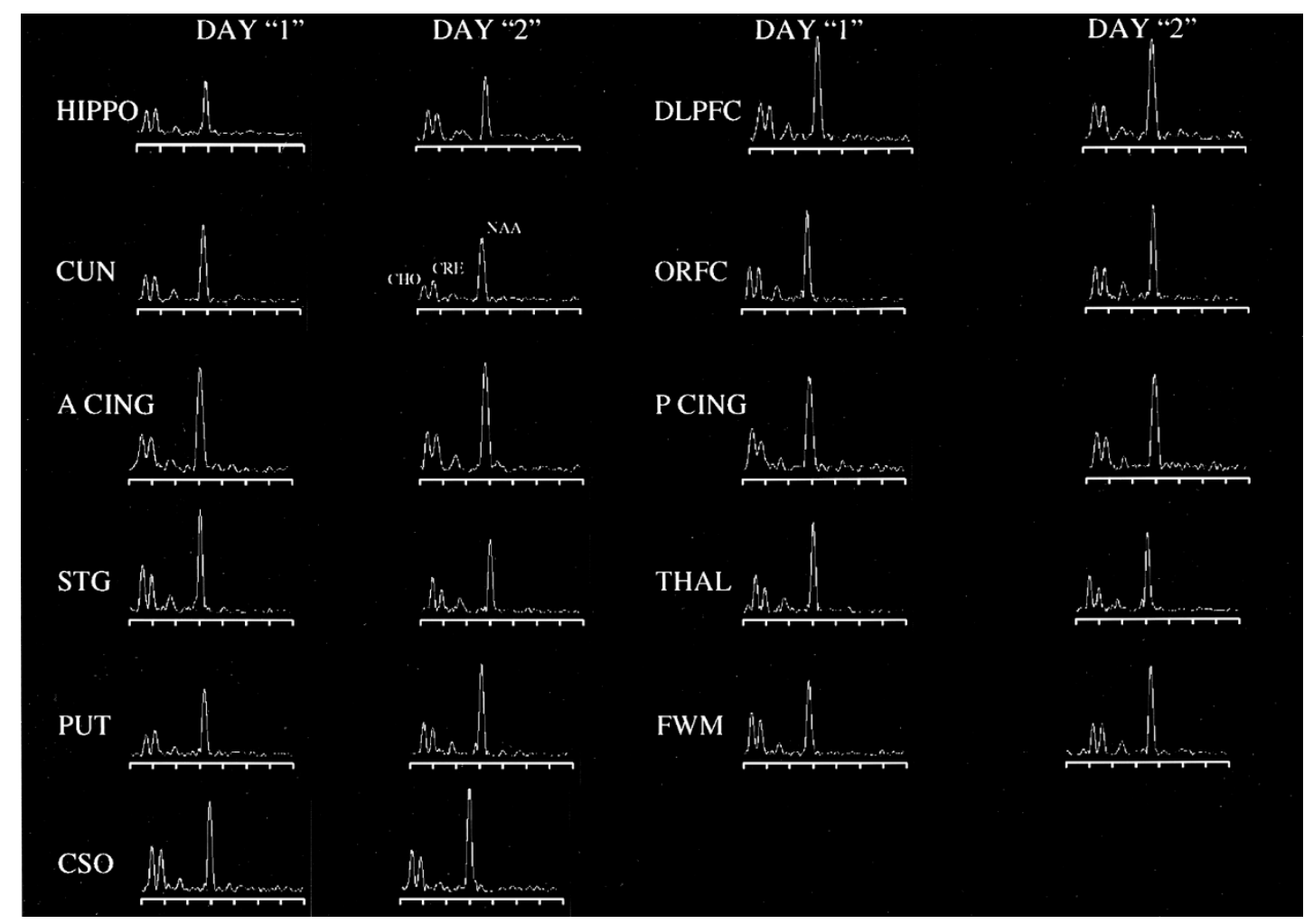

Figure 3. Representative spectra from the normal control in all 11 anatomical regions on day 1 and 2.

df $1,18, p<.01)$ and NAA $/ \mathrm{CHO}(\mathrm{F}=6.3, d f 1,18, p<.02$ and $\mathrm{F}=7.7, d f 1,18, p<.01)$. Post-hoc analysis showed that patients with schizophrenia had a significant bilateral reduction of NAA/CRE $(p<.0001$ and $p<.01)$ and NAA/CHO $(p<.02$ and $p<.01)$. No main effect of hemisphere or interaction with diagnosis was found for NAA/CRE and NAA/CHO both on day 1 and 2. No main effect or interaction was found for $\mathrm{CHO} / \mathrm{CRE}$.

ANOVA revealed sporadic effects of hemisphere and no interaction of diagnosis by hemisphere. None of the sporadic results, which were not based on a priori hypotheses, survived an appropriate Bonferroni correction for the number of regions, even at the trend level. No LAC signal was identified in patients or normal controls. This is consistent with the normal intracere- bral LAC concentration (about $0.5 \mathrm{mmol} / \mathrm{g}$ ), which is close to or below the current detection limit of the method.

The repeated measures ANOVA with diagnosis and time as factors showed statistically significant effects due only to diagnosis in HIPPO and DLPFC for NAA/ CRE and NAA/CHO. No other statistically significant effect or interaction was found for any of the ROIs for all metabolite ratios.

For each metabolite ratio, the variability between subjects was almost greater than the variability within a subject across time. The only exceptions were: NAA/ $\mathrm{CHO}$ in left (l) OC and right (r) FWM of controls; NAA/CHO in 1 OC and $\mathrm{r}$ CSO of patients; NAA/CRE in $1 \mathrm{OC}$ and $\mathrm{r}$ THAL of controls; NAA/CRE in 1 and $\mathrm{r} A$

Table 2. Within-day Results shown by ANOVA on HIPPO and DLPFC

\begin{tabular}{lcccccc}
\hline & $\begin{array}{c}\text { Day 1 } \\
\text { NAA/CRE }\end{array}$ & $\begin{array}{c}\text { Day 2 } \\
\text { NAA/CRE }\end{array}$ & $\begin{array}{c}\text { Day 1 } \\
\text { NAA/CHO }\end{array}$ & $\begin{array}{c}\text { Day 2 } \\
\text { NAA/CHO }\end{array}$ & $\begin{array}{c}\text { Day 1 } \\
\text { CHO/CRE }\end{array}$ & $\begin{array}{c}\text { Day 2 } \\
\text { CHO/CRE }\end{array}$ \\
\hline HIPPO & & & & & & \\
patients & 1.71 & 1.82 & 1.36 & 1.54 & 1.26 & 1.23 \\
controls & 2.05 & 2.15 & 1.63 & 1.79 & 1.27 & 1.2 \\
$p$ & .003 & .003 & .01 & .01 & .8 & .7 \\
DLPFC & & & & & & \\
patients & 2.45 & 2.61 & 2.21 & 2.6 & 1.07 & 1.01 \\
controls & 2.86 & 2.96 & 2.6 & 2.9 & 1.11 & 1.08 \\
$p$ & .001 & .01 & .02 & .01 & .4 & .3 \\
\hline
\end{tabular}


CING, in $r$ THAL, in $1 \mathrm{OC}$ and 1 and $\mathrm{r}$ PUT of patients; $\mathrm{CHO} / \mathrm{CRE}$ in $1 \mathrm{OC}$ of controls. The ICCs of the ROIs reached statistical significance only in a few instances. No correlation was found between the size of the ROIs and metabolite ratios.

On the whole, CVs were fairly low (see Figures 4-6). The CVs of normal controls and patients with schizophrenia were comparable, though the patients tended to have slightly greater $\mathrm{CVs}$ (none significant by twotailed $t$-test: NAA/CRE $p>.6$; NAA/CHO $p>.7$; $\mathrm{CHO} / \mathrm{CRE} p>$.5). Overall, NAA/CRE and CHO/CRE had comparable CVs, which were also always lower than NAA/CHO ones. No statistically significant correlation (Spearman rank analysis) was found between the size of the ROIs and the CVs.

\section{DISCUSSION}

The main findings of the present multislice ${ }^{1} \mathrm{H}$-MRSI study are: (1) patients with schizophrenia show, at least over a mean 3-month time interval, a stable pattern of ${ }^{1} \mathrm{H}-\mathrm{MRSI}$ findings, i.e., bilateral reductions of NAA/ $\mathrm{CRE}$ and NAA/CHO in HIPPO and DLPFC; (2) ${ }^{1} \mathrm{H}-$ MRSI group data in patients and controls do not show significant metabolite differences between day 1 and day 2; (3) between-subject variability was always greater than within subject variability. However, the ICCs showed that the predictability of absolute individual regional metabolite ratios over a mean 3-month period within a subject is low. The consistent differences between groups in NAA ratios are probably explained by the large effect size. (4) ${ }^{1} \mathrm{H}-\mathrm{MRSI}$ group data show rela- tively low variability (as measured by the $\mathrm{CVs}$ ) both in patients and normal controls, especially for NAA/CRE and $\mathrm{CHO} / \mathrm{CRE}$; (5) different ROIs have different CVs.

This study was designed to assess the reproducibility over time of ${ }^{1} \mathrm{H}$-MRSI findings in a comparison of a group of patients with schizophrenia and a group of healthy controls. Patients with schizophrenia had significantly lower NAA/CRE and NAA/CHO in HIPPO and in DLPFC on both experimental days. Therefore, the regionally specific pattern of bilateral reduction of NAA ratios in HIPPO and DLPFC found in patients with schizophrenia is stable, at least over a mean 3-month time period. The present ${ }^{1} \mathrm{H}$-MRSI study confirms and extends previous data on the specific regionality of neuronal involvement in schizophrenia and constitutes a basis for future ${ }^{1} \mathrm{H}$-MRSI studies.

Our ${ }^{1} \mathrm{H}$-MRSI group data show relatively low variability both in patients and normal controls, especially for NAA/CRE and CHO/CRE. These results are consistent with previous studies (Tedeschi et al. 1995b; Frahm et al. 1989; Hennig et al. 1992), which have shown that CRE (which measures both phosphocreatine and creatine at equilibrium in cell energy metabolism) reveals the lowest variability among the metabolites studied by ${ }^{1} \mathrm{H}-\mathrm{MRS}$ (Frahm et al. 1989; Hennig et al. 1992). Indeed, the two least variable ratios have CRE as the denominator.

It is important to note that CVs varied across the ROIs. This may be attributable to technical factors, such as local field inhomogeneities and spectral "bleeding," as well as differences in cellularity. Because gray and white matter express significantly different metabolite ratios (Tedeschi et al. 1995b) and because of differences

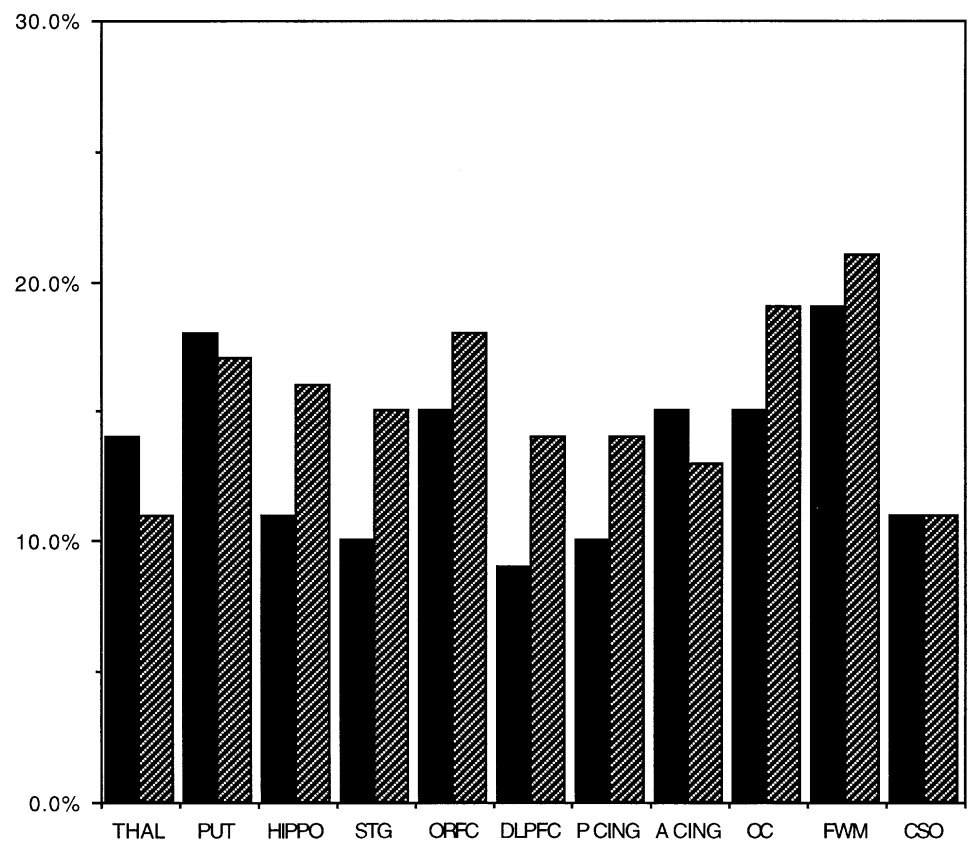

Figure 4. NAA/CRE $\mathrm{CVs}$ in

Controls $\mathbb{Z}$ Patients patients and controls for all ROIs. See text for explanation of ROI abbreviations. 


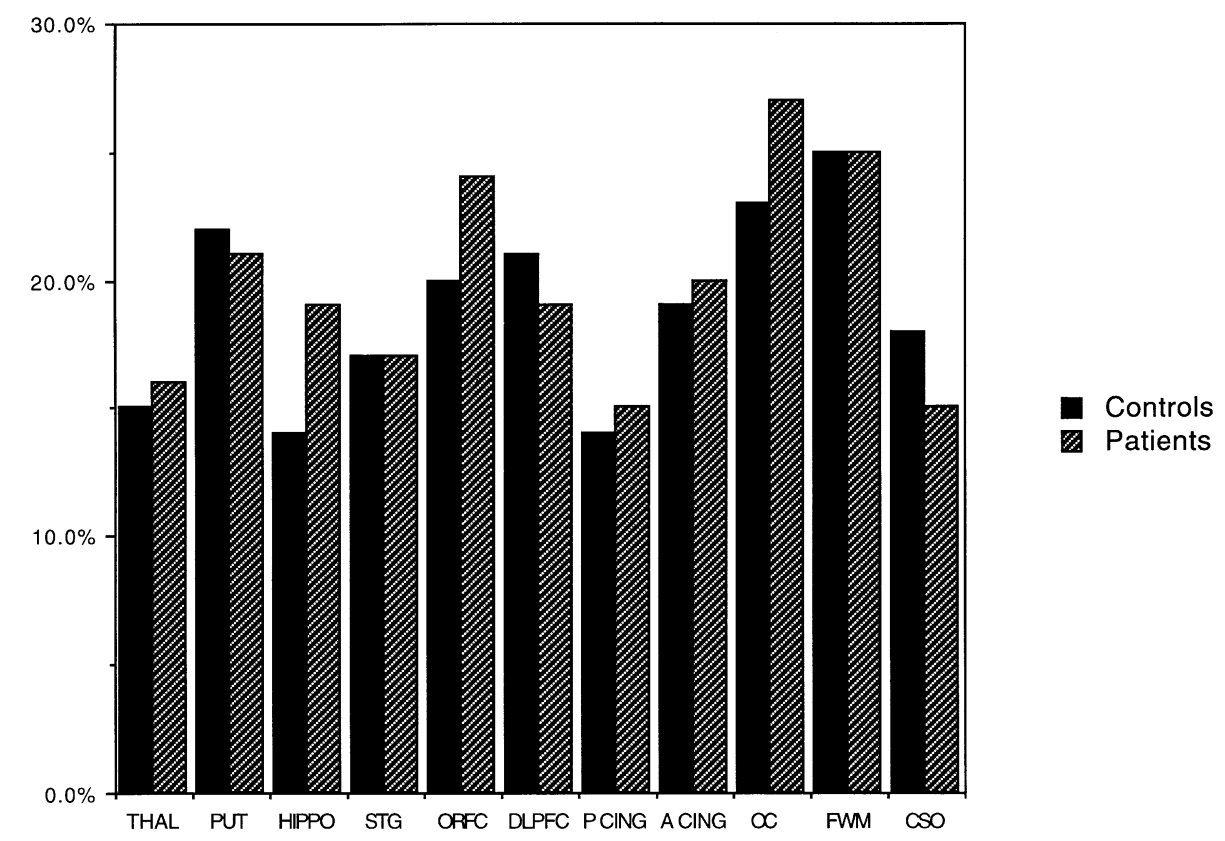

Figure 5. NAA/CHO CVs in patients and controls for all ROIs. in volume of gray and white matter included in any ROI, it is important to reproduce the same anatomical region in the repeat study and to differentiate as much as possible between white and gray matter. These factors have to be taken into account when planning follow-up studies. The lack of significant ICCs is also probably related to these factors, as well as to the small sample size and the relatively long time interval between the two repeat studies.

Between-subject variance was greater than withinsubject variance across time. This trend was true both for patients and controls and is consistent with the assumption that each subject has his/her own ${ }^{1} \mathrm{H}-\mathrm{MRS}$ chemical characteristics that differ slightly from that of others but are fairly uniform over time. The implications of the ICC results in the context of the group analyses are several. When using a rigorous statistical approach (ICCs), ${ }^{1} \mathrm{H}-\mathrm{MRSI}$ individual values show poor regional reliability, especially over relatively long periods of time. The consequence is that it is not possible, like with many other in vivo physiological/chemical techniques, to perform reliable statistical comparisons

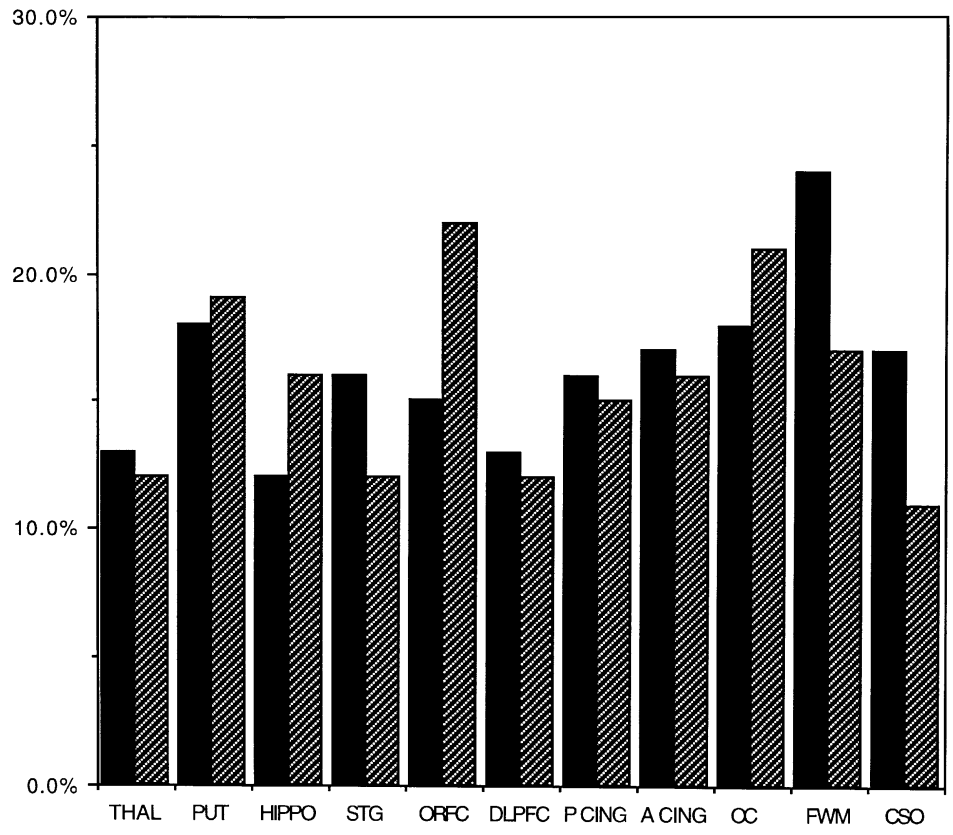

Controls

Patients
Figure 6. $\mathrm{CHO} / \mathrm{CRE} \mathrm{CVS}$ in patients and controls for all ROIs. 
using a single individual's ${ }^{1} \mathrm{H}-\mathrm{MRSI}$ data. Thus, ${ }^{1} \mathrm{H}-$ MRSI data require group averaging to explore main effects such as diagnosis, time, treatment, etc. We are currently exploring transformations approaches to the data that may yield more predictable individual results.

Whereas several studies have used ${ }^{1} \mathrm{H}$-MRS techniques to perform longitudinal studies in patients with various pathological conditions, only three studies have specifically assessed the variability of the method. Narayana et al. (1991) performed a single-voxel (27 cc voxel) ${ }^{1} \mathrm{H}$-MRS study of the frontal lobe in six normal controls examined four times over a period of 6 months. As reported in Jackson et al. (1994), they found CVs on the order of $36 \%$ for NAA/CRE and $39 \%$ for CHO/ CRE. Our results on normal controls obtained in DLPFC, ORFC, and FWM show CVs of, respectively, 9\%, 15\%, and $19 \%$ for NAA/CRE and $13 \%, 15 \%$, and $24 \%$ for CHO/CRE. Jackson et al. (1994) performed a short TE ${ }^{1}$ H-MRSI $(15 \times 15 \times 15 \mathrm{~mm}$ of ideal voxel size $)$ study involving a single slice just superior to the corpus callosum in five normal volunteers who underwent four repeated studies. The overall CVs were $17.5 \%$ for NAA/ $\mathrm{CRE}$ and $16 \%$ for $\mathrm{CHO} / \mathrm{CRE}$. These results are comparable with our normal control data in CSO, A CING and P CING, wherein we found, respectively, CVs of $11 \%$, $15 \%$, and $10 \%$ for NAA/CRE and $17 \%, 17 \%$, and $16 \%$ for CHO/CRE. Charles et al. (1996) performed a short TE ${ }^{1} \mathrm{H}-\mathrm{MRSI}$ study with a single slice approximately parallel to the canthomeatal line passing through the basal ganglia and the genu of the corpus callosum. Subjects were studied twice in 10 days. The authors averaged the date throughout the entire slice (63 voxels) and obtained percentage variation of $5.7 \pm 51.5$ for NAA/ CRE, $14.1 \pm 55.1$ for $\mathrm{NAA} / \mathrm{CHO}$ and $4.1 \pm 56.9$ for $\mathrm{CHO} / \mathrm{CRE}$. The ICCs of the ratios were respectively $0.76,0.77$, and 0.66 . These three earlier studies, together with our own, show that variability becomes smaller when higher spatial resolution techniques are used. Smaller voxel size involves lesser partial volume effects, better separation between white and gray matter (that have different metabolite concentrations), and higher accuracy in choosing ROIs in repeat studies. The inconsistency between our data and those of Charles et al. (1996) regarding the ICCs might be explained by differences in methodology: (1) the authors studied the subjects twice with a 10-day time interval, whereas ours was a mean of 3 months; (2) their results were obtained from the whole spectroscopic slice, whereas we tried to differentiate between anatomical regions to obtain regional patterns.

In conclusion, we have demonstrated that regional chemical pathology involving HIPPO and DLPFC bilaterally is a relatively stable finding with ${ }^{1} \mathrm{H}-\mathrm{MRSI}$ in patients with schizophrenia. Our results caution that, when planning longitudinal studies with ${ }^{1} \mathrm{H}-\mathrm{MRSI}$, it is important to control regional variance, as different ana- tomical regions show different variabilities. The possibility of differentiating anatomical regions with good reproducibility are benefits of high spatial resolution techniques. Moreover, once the "normal" variability of this particular technique has been established, larger changes in metabolites found in longitudinal studies are likely attributable to physiopathology changes.

\section{ACKNOWLEDGMENTS}

We are grateful to Dr. Chrit T.W. Moonen, Dr. Michael Knable, and Dr. Alan S. Barnett for helpful suggestions. This work was performed in the In Vivo NMR Research Center at the National Institutes of Health, Washington, DC.

\section{REFERENCES}

Alger JR, Frank JA, Bizzi A, Fulham M, DeSouza B, Duhaney MO, Inscoe SW, Black JL, van Zijl PCM, Moonen CTW, Di Chiro G (1990): Metabolism of human gliomas: Assessment with H-1 spectroscopy and F-18 fluorodeoxyglucose PET. Radiology 177:633-641

Arnold DL, Riess GT, Matthews PM, Francis GS, Collins DL, Wolfson C, Antel JP (1994): Use of proton magnetic resonance spectroscopy for monitoring disease progression in multiple sclerosis. Ann Neurol 36:76-82

Barker PB, Breiter SN, Soher BJ, Chatham JC, Forder JR, Samphilipo MA, Magee CA, Anderson JH (1994a): Quantitative proton spectroscopy of canine brain: In vivo and in vitro correlations. Magn Reson Med 32(2): 157-163

Barker PB, Gillard JH, van Zijl PCM, Soher BJ, Hanley DF, Agildere AM, Oppenheimer SM, Bryan RN (1994b): Acute stroke: Evaluation with serial proton MR spectroscopic imaging. Radiology 192(3):723-732

Barker PB, Lee RR, McArthur JC (1995): AIDS dementia complex: Evaluation with proton MR spectroscopic imaging. Radiology 195:58-64

Bartko JJ, Carpenter WT Jr (1976): On the methods and theory of reliability. J Nerv Ment Dis 163:307-317

Bertolino A, Nawroz S, Mattay VS, Barnett AS, Duyn JH, Moonen CTW, Frank JA, Tedeschi G, Weinberger DR (1996): A specific pattern of neurochemical pathology in schizophrenia as assessed by multislice proton magnetic resonance spectroscopic imaging. Am J Psychiatry; 153:1554-1563

Bizzi A, Movsas B, Tedeschi G, Phillips CL, Okunieff P, Alger JR, Di Chiro G (1995): Response of non-Hodgkin lymphoma to radiation therapy: Early and long-term assessment with H-1 MR spectroscopic imaging. Radiology 194:271-276

Buckley PF, Moore C, Long H, Larkin C, Thompson P, Mulvany F, Redmond O, Stack JP, Ennis JT, Waddington JL (1994): $1 \mathrm{H}$ Magnetic resonance spectroscopy of the left temporal and frontal lobes in schizophrenia: Clinical, neurodevelopmental and cognitive correlates. Biol Psychiatry 36:792-800 
Cazzaniga S, Schold SC Jr, Sostman HD, Charles HC (1994): Effects of therapy on the 1H NMR spectrum of a human glioma line. Magn Reson Imaging 12(6):945-950

Charles HC, Lazeyras F, Tupler LA, Krishnan KRR (1996): Reproducibility of high spatial resolution proton magnetic resonance spectroscopic imaging in the human brain. MRM 35:606-610

Connelly A, Jackson GD, Duncan JS, King MD, Gadian DG (1994): Magnetic resonance spectroscopy in temporal lobe epilepsy. Neurology 44:1411-1417

Davie CA, Hawkins CP, Barker GJ, Brennan J, Tofts PF, Miller DH, McDonald WI (1994): Serial proton magnetic resonance spectroscopy in acute multiple sclerosis lesions. Brain 117:49-58

Duyn JH, Gillen J, Sobering G, van Zijl PC, Moonen CTW (1993): Multisection proton MR spectroscopic imaging of the brain. Radiology 188:277-282

Frahm J, Bruhn H, Gyngell ML, Merboldt, Hanicke W, Sauter R (1989): Localized proton NMR spectroscopy in different regions of the human brain in vivo. Relaxation times and concentrations of cerebral metabolites. Magn Reson Med 11:47-63

Fukuzako H, Takeuchi K, Hokazono Y, Fukuzako T, Yamada K, Hashiguchi T, Obo Y, Ueyama K, Takigawa M, Fujimoto T (1995): Proton magnetic resonance spectroscopy of the left medial temporal and frontal lobes in chronic schizophrenia: Preliminary report. Psychiatry Res Neuroimaging 61:193-200

Hennig J, Pfister H, Ernst T, Ott D (1992): Direct absolute quantification of metabolites in the human brain with in vivo localized spectroscopy. NMR Biomed 5:193-199

Hetherington H, Kuzniecky R, Pan J, Mason G, Morawetz R, Harris C, Faught E, Vaughan T, Pohost G (1995): Proton nuclear magnetic resonance spectroscopic imaging of human temporal lobe epilepsy at $4.1 \mathrm{~T}$. Ann Neurol 38:396-404

Jackson EF, Doyle TJ, Wolinsky JS, Narayana PA (1994): Short TE hydrogen-1 spectroscopic imaging of normal human brain: Reproducibility studies. JMRI 4:545:551

Jenkins BG, Koroshetz WJ, Beal FM, Rosen BR (1993): Evidence for impairment of energy metabolism in vivo in Huntington's disease using localized 1H NMR spectroscopy. Neurology 43:2689-2695

Kruse B, Barker PB, van Zijl PCM, Duyn JH, Moonen CTW, Mosr HW (1994): Multislice proton magnetic resonance spectroscopic imaging in $x$-linked adrenoleukodystrophy. Ann Neurol 36:595-608

Maier M, Ron MA, Barker GJ, Tofts PS (1995): Proton magnetic resonance spectroscopy: An in vivo method of estimating hippocampal neuronal depletion in schizophrenia. Psychol Med 25:1201-1209

Meyerhoff DJ, MacKay S, Constans J-M, Norman D, Van Dyke C, Fein G, Weiner MW (1994): Axonal injury and membrane alterations in Alzheimer's disease suggested by in vivo proton magnetic resonance spectroscopic imaging. Ann Neurol 36:40-47

Miller BL (1991): A review of chemical issues in 1H NMR spectroscopy: N-acetyl-L-aspartate, creatine and choline. NMR Biomed 4:47-52

Murata T, Koshino Y, Omori M, Murata I, Nishio M, Horie T, Umezawa $\mathrm{Y}$, Isaki K, Kimura H, Itoh S, Maeda M, Ishii $\mathrm{Y}$ (1993): In vivo proton magnetic resonance spectroscopy study on premature aging in adult Down's syndrome. Biol Psychiatry 34:290-297

Nakakoshi T, Matsuzawa H, Houkin K, Miyasaka K, Arimoto T (1994): Two cases of proton MR spectroscopy of the brain after irradiation. Radiat Med 12:139-142

Narayana PA, Johnston D, Flamig D (1991): In vivo proton magnetic resonance spectroscopy studies of human brain. Magn Reson Imaging 9:303-308

Nasrallah HA, Skinner TE, Schmalbrock P, Robitaille PM (1994): Proton magnetic resonance spectroscopy of the hippocampal formation in schizophrenia: A pilot study. Br J Psychiatry 165:481-485

Renshaw PF, Yurgelun-Todd DA, Tohen M, Gruber S, Cohen B (1995): Temporal lobe proton magnetic resonance spectroscopy of patients with first-episode psychosis. Am J Psychiatry 152:444-446

Roser W, Hagberg G, Mader I, Brunnschweiler H, Radue EW, Seelig J, Kappos L (1995): Proton MRS of gadolinium-enhancing MS plaques and metabolic changes in normal-appearing white matter. Magn Reson Med 33(6):811-817

Tedeschi G, Schiffmann R, Barton NW, Shih HH-L, Gospe SM, Brady RO, Alger JR, Di Chiro G (1995a): Proton magnetic resonance spectroscopic imaging in childhood ataxia with diffuse central nervous system hypomyelination. Neurology 45:1526-1532

Tedeschi G, Bertolino A, Righini A, Campbell G, Raman R, Duyn JH, Moonen CTW, Alger JR, Di Chiro G (1995b): Brain regional distribution pattern of metabolite signal intensities in young adults by proton magnetic resonance spectroscopic imaging. Neurology 45:1384-1391

Tedeschi G, Bertolino A, Massaquoi SG, Campbell G, Patronas NJ, Bonavita S, Barnett AS, Alger JR, Hallett M (1996): Proton magnetic resonance spectroscopic imaging in patients with cerebellar degeneration. Ann Neurol 39: 71-78

Urenjak J, Williams SR, Gadian DG, Noble M (1993): Proton nuclear magnetic resonance spectroscopy unambiguously identifies different neural cell types. J Neurosci 13:981-989

Vion-Dury J, Nicoli F, Salvan AM, Confort-Gouny S, Dhiver C, Cozzone P (1995): Reversal of brain metabolic alterations with zidovudine detected by proton localised magnetic resonance spectroscopy. Lancet 345:60-61

Weinberger DR (1995): Schizophrenia: From neuropathology to neurodevelopment. Lancet 346:552-557

Weinberger DR, Lipska BK (1995): Cortical maldevelopment, anti-psychotic drugs and schizophrenia: A search for common ground. Schizophr Res 16:87-110

Yurgelun-Todd DA, Renshaw PF, Gruber SA, Waternaux CM, Cohen BM (1996): Proton magnetic resonance spectroscopy of the temporal lobes in schizophrenics and normal controls. Schizophr Res 19:55-59 